\title{
2005s-03
}

\section{Exact Multivariate Tests of Asset Pricing Models with Stable Asymmetric Distributions}

\author{
Marie-Claude Beaulieu, Jean-Marie Dufour, \\ Lynda Khalaf
}

Série Scientifique
Scientific Series

Montréal

Août 2004

(publié en février 2005)

(C) 2005 Marie-Claude Beaulieu, Jean-Marie Dufour, Lynda Khalaf. Tous droits réservés. All rights reserved. Reproduction partielle permise avec citation du document source, incluant la notice $\mathbb{C}$.

Short sections may be quoted without explicit permission, if full credit, including $\mathbb{C}$ notice, is given to the source.
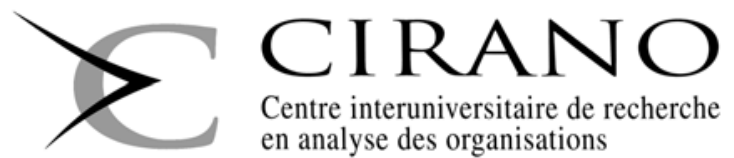

Centre interuniversitaire de recherche en analyse des organisations 


\section{CIRANO}

Le CIRANO est un organisme sans but lucratif constitué en vertu de la Loi des compagnies du Québec. Le financement de son infrastructure et de ses activités de recherche provient des cotisations de ses organisations-membres, d'une subvention d'infrastructure du Ministère du Développement économique et régional et de la Recherche, de même que des subventions et mandats obtenus par ses équipes de recherche.

CIRANO is a private non-profit organization incorporated under the Québec Companies Act. Its infrastructure and research activities are funded through fees paid by member organizations, an infrastructure grant from the Ministère du Développement économique et régional et de la Recherche, and grants and research mandates obtained by its research teams.

PARTENAIRE MAJEUR

$$
\text { Les organisations-partenaires / The Partner Organizations }
$$

. Ministère du Développement économique et régional et de la Recherche [MDERR]

PARTENAIRES

. Alcan inc.

. Axa Canada

. Banque du Canada

. Banque Laurentienne du Canada

. Banque Nationale du Canada

. Banque Royale du Canada

. Bell Canada

. BMO Groupe Financier

. Bombardier

. Bourse de Montréal

. Caisse de dépôt et placement du Québec

. Développement des ressources humaines Canada [DRHC]

. Fédération des caisses Desjardins du Québec

. GazMétro

. Groupe financier Norshield

. Hydro-Québec

. Industrie Canada

. Ministère des Finances du Québec

. Pratt \& Whitney Canada Inc.

. Raymond Chabot Grant Thornton

. Ville de Montréal

. École Polytechnique de Montréal

. HEC Montréal

. Université Concordia

. Université de Montréal

. Université du Québec

. Université du Québec à Montréal

. Université Laval

. Université McGill

. Université de Sherbrooke

ASSOCIE A :

. Institut de Finance Mathématique de Montréal (IFM²)

. Laboratoires universitaires Bell Canada

. Réseau de calcul et de modélisation mathématique $\left[\mathrm{RCM}^{2}\right]$

. Réseau de centres d'excellence MITACS (Les mathématiques des technologies de l'information et des systèmes complexes)

Les cahiers de la série scientifique $(\mathrm{CS})$ visent à rendre accessibles des résultats de recherche effectuée au CIRANO afin de susciter échanges et commentaires. Ces cahiers sont écrits dans le style des publications scientifiques. Les idées et les opinions émises sont sous l'unique responsabilité des auteurs et ne représentent pas nécessairement les positions du CIRANO ou de ses partenaires.

This paper presents research carried out at CIRANO and aims at encouraging discussion and comment. The observations and viewpoints expressed are the sole responsibility of the authors. They do not necessarily represent positions of CIRANO or its partners. 


\title{
Exact Multivariate Tests of Asset Pricing Models with Stable Asymmetric Distributions"
}

\author{
Marie-Claude Beaulieu ${ }^{\dagger}$, Jean-Marie Dufour ${ }^{*}$ Lynda Khalaf ${ }^{\S}$
}

\begin{abstract}
Résumé / Abstract
Dans cet article, nous proposons des méthodes d'inférence exactes pour des modèles d'évaluation d'actifs (CAPM) qui sont formulés dans le contexte des modèles de régression linéaires multivariés. De plus, ces méthodes permettent de considérer des lois de probabilité stables sur les erreurs du modèle. Il est bien connu que l'hypothèse de normalité des rendements boursiers est habituellement rejetée dans les études empiriques à cause de la présence d'asymétrie et d'aplatissement dans les distributions. Afin de modéliser de tels attributs, nous suggérons une approche qui accommode l'asymétrie et l'aplatissement dans les distributions sans avoir recours à des approximations de grands échantillons. Les méthodes suggérées sont basées sur des tests de Monte Carlo. Des tests diagnostiques multivariés sont formellement inclus dans l'analyse afin de s'assurer que les distributions d'erreurs considérées sont raisonnables pour les données étudiées. Ces tests permettent la construction de régions de confiance exactes pour les paramètres d'asymétrie et d'aplatissement des erreurs dans le cas de lois stables. Nous proposons des tests d'efficacité du portefeuille de référence (i.e., pour la nullité des constantes) qui tiennent explicitement compte de la présence de paramètres de nuisance dans les distributions stables. Les méthodes proposées sont appliquées aux rendements de 12 portefeuilles constitués d'actifs négociés à la bourse de New York (NYSE) sur la période s'étalant de 1926 à 1995 (par sous-périodes de cinq ans). Nos résultats montrent que l'utilisation de distributions stables possiblement asymétriques produit une amélioration statistique importante dans la représentation de la distribution et mène à moins de rejet de l'hypothèse d'efficacité du portefeuille de marché.
\end{abstract}

Mots clés : modèle d'évaluation d'actifs financiers; efficience de portefeuille; non-

normalité; modèle de régression multivarié; loi stable; asymétrie; aplatissement; hypothèse linéaire uniforme; test exact; test de Monte Carlo; paramètres de nuisance; tests diagnostiques

\footnotetext{
* This work was supported by the Canada Research Chair Program (Chair in Econometrics, Université de Montréal), the Alexander-von-Humboldt Foundation (Germany), the Institut de finance mathématique de Montréal (IFM2), the Canadian Network of Centres of Excellence [program on Mathematics of Information Technology and Complex Systems (MITACS)], the Canada Council for the Arts (Killam Fellowship), the Natural Sciences and Engineering Research Council of Canada, the Social Sciences and Humanities Research Council of Canada, the Fonds de recherche sur la société et la culture (Québec), and the Fonds de recherche sur la nature et les technologies (Québec). This paper was also partly written at the University of Amsterdam and the Centre de recherche en économie et statistique (CREST, INSÉE, Paris).

${ }^{\dagger}$ Centre interuniversitaire sur le risque, les politiques économiques et l'emploi (CIRPÉE), CIRANO, and Département de finance et assurance, Université Laval. Mailing address: Département de finance et assurance, Pavillon Palasis-Prince, Université Laval, Ste-Foy, Québec, Canada G1K 7P4. Tel: 1 (418) 656-2926, Fax: 1 (418) 656-2624; e-mail: Marie-Claude.Beaulieu@,fas.ulaval.ca

" Canada Research Chair Holder (Econometrics). Centre interuniversitaire de recherche en analyse des organisations (CIRANO), Centre interuniversitaire de recherche en économie quantitative (CIREQ), and Département de sciences économiques, Université de Montréal. Mailing address: Département de sciences économiques, Université de Montréal, C.P. 6128 succursale Centre-ville, Montréal, Québec, Canada H3C 3J7. Tel: 1 (514) 343-2400; Fax: 1 (514) 343-5831; e-mail: jean.marie.dufour@umontreal.ca. Web page: http://www.fas.umontreal.ca/SCECO/Dufour

${ }^{\S}$ Canada Research Chair Holder (Environmental and Financial Econometric Analysis). Centre interuniversitaire de recherche en économie quantitative (CIREQ), Groupe de recherche en économie de l'énergie, de l'environnement et des ressources naturelles (GREEN), and Département d'économique, Université Laval. Mailing address: Département d'économique, Université Laval, Pavillon J.-A. De Sève, Ste-Foy, Québec, Canada, G1K 7P4. Tel: 1 (418) 656-2131\#2409; Fax: 1 (418) 656-7412; e-mail: lynda.khalaf@ecn.ulaval.ca
} 
In this paper, we propose exact inference procedures for asset pricing models that can be formulated in the framework of a multivariate linear regression (CAPM), allowing for stable error distributions. The normality assumption on the distribution of stock returns is usually rejected in empirical studies, due to excess kurtosis and asymmetry. To model such data, we propose a comprehensive statistical approach which allows for alternative - possibly asymmetric - heavy tailed distributions without the use of large-sample approximations. The methods suggested are based on Monte Carlo test techniques. Goodness-of-fit tests are formally incorporated to ensure that the error distributions considered are empirically sustainable, from which exact confidence sets for the unknown tail area and asymmetry parameters of the stable error distribution are derived. Tests for the efficiency of the market portfolio (zero intercepts) which explicitly allow for the presence of (unknown) nuisance parameter in the stable error distribution are derived. The methods proposed are applied to monthly returns on 12 portfolios of the New York Stock Exchange over the period 1926-1995 (5 year subperiods). We find that stable possibly skewed distributions provide statistically significant improvement in goodness-of-fit and lead to fewer rejections of the efficiency hypothesis.

Keywords: capital asset pricing model; mean-variance efficiency; non-normality; multivariate linear regression; stable distribution; skewness; kurtosis; asymmetry; uniform linear hypothesis; exact test; Monte Carlo test; nuisance parameter; specification test; diagnostics

Codes JEL : C3; C12; C33; C15; G1; G12; G14 


\section{Contents}

$\begin{array}{ll}\text { 1. Introduction } & 1\end{array}$

2. Framework 3

3. Statistical method 5

$\begin{array}{lr}\text { 4. Empirical analysis } & 8\end{array}$

$\begin{array}{ll}\text { 5. Conclusion } & 12\end{array}$

\section{List of Definitions, Propositions and Theorems}

3.1 Theorem : Distribution of the quasi-LR CAPM test statistic $\ldots \ldots \ldots$

\section{List of Tables}

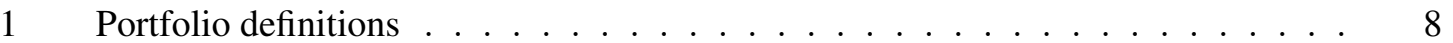

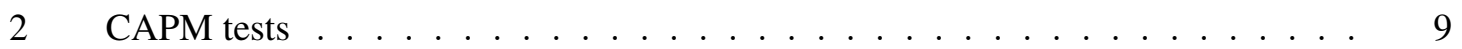

3 Supremum p-values for various positive skewness measures . . . . . . . . . . 11

4 Supremum p-values for various negative skewness measures . . . . . . . . . . 11 


\section{Introduction}

An important problem in empirical finance consists in testing the efficiency of a market portfolio by assessing the statistical significance of the intercepts of a multivariate linear regression (MLR) on asset returns [the capital asset pricing model (CAPM)]; see MacKinlay (1987), Jobson and Korkie (1989), Gibbons, Ross and Shanken (1989, henceforth GRS), Shanken (1996), Campbell, Lo and MacKinlay (1997, Chapters 5 and 6), Stewart (1997), and Fama and French (2003). Traditional statistical theory supplies a reliable distributional theory mainly in the case where the disturbances in the model follow a Gaussian distribution; see, for example, Anderson (1984, chapters 8 and 13) and Rao (1973, chapter 8). However, in financial data, the Gaussian assumption is typically inappropriate, because asset returns often exhibit excess kurtosis and asymmetries; see, for example, Fama (1965), Baillie and Bollerslev (1989), Beaulieu (1998), and Dufour, Khalaf and Beaulieu (2003). Further, asymptotic approximations aimed at relaxing the Gaussian assumption tend to be unreliable in multivariate models such as those considered in CAPM applications, especially when the number of equations (or assets) is not small; see Campbell et al. (1997, Chapter 5), Gibbons et al. (1989), Shanken (1996, Section 3.4.2) and Dufour and Khalaf (2002b). Consequently, it is important from an inference viewpoint that we approach this problem from a finite sample perspective. ${ }^{1}$

In recent work [Dufour et al. (2003) and Beaulieu, Dufour and Khalaf (2004)], we considered this problem by developing exact efficiency tests of the market portfolio in the case where the CAPM disturbances follow $t$ distributions or normal mixtures. In particular, we observed that: (i) monthly returns reject multivariate normality conclusively, and (ii) CAPM-based on the assumption of elliptical errors yield less rejections than those based on the (erroneous) normality assumption. The latter result obtains if the (unknown) parameters underlying the elliptical error distribution are formally accounted for. ${ }^{2}$ Indeed, the whole issue centers on the uncertainty associated with unknown (nuisance) parameters, one of the main difficulties which complicate the development of exact tests. This analysis was however restricted to symmetric error distributions.

In the present paper, we consider distributional models that can accommodate more pronounced skewness and kurtosis. Specifically, we study the case where the disturbances in a CAPM regression can follow stable possibly asymmetric distributions. Our results reveal notable differences with respect to the mainstream elliptical framework. Besides being consistent with optimization arguments underlying the CAPM [see Samuelson (1967)], the family of stable distributions is entailed by various central limit arguments in probability theory (as an alternative to the Gaussian distribution) and has often been suggested as a useful model for return and price distributions in finance; see, for example, Mandelbrot (1963), Ibragimov and Linnik (1975), Zolotarev (1986), Cambanis, Samorodnitsky and Taqqu (1991), Samorodnitsky and Taqqu (1994), Embrechts, Klüppelberg and Mikosch

\footnotetext{
${ }^{1}$ For more general discussions of the importance of developing finite-sample statistical procedures, see Dufour (1997, 2003).

${ }^{2}$ Concerning normality tests, our procedures achieve size control exactly, so test rejections cannot be spurious by construction. Concerning tests on intercepts, we formally demonstrate location-scale invariance of the commonly used procedures for the context at hand. Since the normal distribution is completely defined by its mean and variance, nuisance parameter-free test procedures can easily be derived. Non-normal distributions raise further nuisance parameter problems; examples include the number of degrees of freedom, for a multivariate Student $t$ distribution, and the probability-ofmixing and scale-ratio parameters for normal mixtures.
} 
(1997), Rachev, Kim and Mittnik (1999a, 1999b), Uchaikin and Zolotarev (1999), Adler, Feldman and Taqqu (2000), Mittnik, Paolella and Rachev (2000), Rachev and Mittnik (2000), and Meerschaert and Scheffler (2001). One should note, however, that tests and confidence sets which have been proposed for inference on such models are almost always based on asymptotic approximations that can easily be unreliable. Further, standard regularity conditions and asymptotic distributional theory may easily not apply to such distributions (for example, because of heavy tails).

To obtain finite-sample inference for such models, we combine several techniques. First, we obtain finite-sample joint confidence sets for the unknown parameters of the stable distribution (i.e., the tail thickness $\alpha_{s}$ and the asymmetry $\beta_{s}$ ) through the "inversion" of goodness-of-fit tests based on multivariate kurtosis and skewness coefficients computed from model residuals. Second, in view of the complicated distribution of these statistics, we exploit invariance properties of the goodnessof-fit statistics to implement the corresponding tests as finite-sample Monte Carlo (MC) tests [as proposed in Dufour et al. (2003)]. Thirdly, using general results from Dufour and Khalaf (2002b) on hypothesis testing in multivariate linear regressions with non-Gaussian disturbances, we note that finite-sample standard LR-type efficiency tests can easily be obtained as soon as the parameters $\left(\alpha_{s}, \beta_{s}\right)$ of the stable error distribution are specified, again through the application of the MC test technique. Fourth, we exploit a two-stage confidence technique proposed in Dufour (1990), Dufour and Kiviet $(1996,1998)$ and Dufour, Hallin and Mizera (1998) to derive efficiency tests that formally take into account the uncertainty of the stable distribution parameters $\left(\alpha_{s}, \beta_{s}\right)$ by maximizing the MC $p$-values associated with different nuisance parameter values $\left(\alpha_{s}, \beta_{s}\right)$ over a confidence set for the latter built as described in the first step above (with an appropriately selected level).

The technique of MC tests - which plays a crucial role in our approach - is an exact simulationbased inference procedure originally proposed by Dwass (1957) and Barnard (1963). It is related to the parametric bootstrap in the sense that the distribution of the test statistic is simulated under the null hypothesis. When the latter does not involve unknown nuisance parameters, the MC test method controls the size of the procedure perfectly, while bootstrap methods are justified only by asymptotic arguments. The finite-sample theory that underlies MC tests allows one to implement test statistics with very complicated distributions (as long as they can be simulated) and does not require establishing a limit distribution as the sample size goes to infinity (or even the existence of such a distribution). It is easy to see that this feature can be quite convenient when dealing with stable distributions under which standard central limit theorems may not apply. The contrast is even more important when test statistics involve nuisance parameters. Here we use extensions of this MC test technique that allow for the presence of nuisance parameters. The level of the test can be controlled in finite samples as soon as the null distribution of the test statistic can be simulated once the values of the nuisance parameters are set. ${ }^{3}$ This is clearly not the case in bootstrapping, where bootstrap samples are drawn after setting the unknown nuisance parameters at some "consistent" estimate. For further discussion of Monte Carlo test methods, see, for example, Dufour (2002), Dufour and Khalaf (2001, 2002a, 2002b, 2003), Dufour and Kiviet (1996, 1998), Kiviet and Dufour (1997), Dufour, Farhat, Gardiol and Khalaf (1998), Dufour, Khalaf, Bernard and Genest (2004), Dufour

\footnotetext{
${ }^{3}$ In nuisance parameter dependent problems, a test is exact at level $\alpha$ if the largest rejection probability over the nuisance parameter space consistent with the null hypothesis is not greater than $\alpha$ [see Lehmann (1986, sections 3.1 and $3.5)]$.
} 
et al. (2003), and Beaulieu et al. (2004). Since bootstrap-type procedures are gaining popularity in finance [see e.g. Li and Maddala (1996)], we emphasize the importance of using such procedures correctly.

We show that the proposed approach is both practical and useful from an empirical viewpoint by applying it to monthly returns on 12 portfolios of the New York Stock Exchange over the period 1926-1995 (5 year subperiods). Among other things we find that heavy-tailed skewed distributions provide statistically significant improvement in goodness-of-fit and lead to fewer rejections of the efficiency hypothesis. Our results show clearly that the introduction of an asymmetric distribution instead of an elliptical distribution yields noteworthy changes in the decision regarding the efficiency hypothesis of the market portfolio. In our opinion this is an important finding since CAPM rejections are often attributed to the presence of excess kurtosis in stock returns. Further, inference on the tail thickness parameter $\alpha_{s}$ appears to be more precise than inference on the asymmetry parameter $\beta_{s}$.

The paper is organized as follows. Section 2 describes the model and test problem studied. In Section 3, we describe the existing test procedures and we show how extensions allowing for nonnormal distributions are obtained. In Section 4 we report the empirical results. Section 5 concludes and discusses extensions to other asset pricing tests.

\section{Framework}

The framework we consider here is the same one as in Beaulieu et al. (2004):

$$
r_{i t}=a_{i}+b_{i} \tilde{r}_{\mathrm{M} t}+u_{i t}, \quad t=1, \ldots, T, i=1, \ldots, n,
$$

where $r_{i t}=R_{i t}-R_{t}^{F}, \tilde{r}_{\mathrm{M} t}=\tilde{R}_{\mathrm{M} t}-R_{t}^{F}, R^{F}$ is the riskless rate of return, $R_{i t}, i=1, \ldots, n$, are returns on $n$ securities for period $t, \tilde{R}_{\mathrm{M} t}$ is the return on the market portfolio, and $u_{i t}$ is a random disturbance. ${ }^{4}$ In this context, the CAPM entails the following efficiency restrictions:

$$
H_{C A P M}: a_{i}=0, \quad i=1, \ldots, n,
$$

i.e. the intercepts $a_{i}$ are jointly equal to zero [Gibbons et al. (1989)].

The above model can be cast in matrix form as a MLR model:

$$
Y=X B+U
$$

where $Y=\left[Y_{1}, \ldots, Y_{n}\right]$ is a $T \times n$ matrix of dependent variables, $X$ is a $T \times k$ full-column rank matrix of regressors, and

$$
U=\left[U_{1}, \ldots, U_{n}\right]=\left[V_{1}, \ldots, V_{T}\right]^{\prime}
$$

is a $T \times n$ matrix of random disturbances. Specifically, to get (2.1), we set:

$$
Y=\left[r_{1}, \ldots, r_{n}\right], \quad X=\left[\iota_{T}, \tilde{r}_{\mathrm{M}}\right], \quad \iota_{T}=(1, \ldots, 1)^{\prime},
$$

\footnotetext{
${ }^{4}$ For convenience, we focus here on the single beta case. For some discussion of the multi-beta CAPM, see Beaulieu et al. (2004).
} 


$$
r_{i}=\left(r_{1 i}, \ldots, r_{T i}\right)^{\prime}, \quad \tilde{r}_{\mathrm{M}}=\left(\tilde{r}_{1 \mathrm{M}}, \ldots, \tilde{r}_{T \mathrm{M}}\right)^{\prime} .
$$

Further, in the matrix setup, the mean-variance efficiency restriction $H_{C A P M}$ belongs to the class of so-called uniform linear (UL) restrictions, i.e. it has the form

$$
H_{0}: H B=D
$$

where $H$ is an $h \times k$ matrix of rank $h . H_{C A P M}$ corresponds to the case where $h=1, H=(1,0)$ and $D=0$.

In general, asset pricing models impose further restrictions on the error distributions. In particular, the standard CAPM obtains assuming that

$$
V_{1}, \ldots, V_{T} \stackrel{\text { i.i.d. }}{\sim} N[0, \Sigma]
$$

or elliptically symmetric [Ingersoll (1987)]; for recent references, see Hodgson, Linton and Vorkink (2002), Vorkink (2003), Hodgson and Vorkink (2003) and the references cited therein. We consider the more general case

$$
V_{t}=J W_{t}, \quad t=1, \ldots, T,
$$

where $J$ is an unknown nonsingular matrix, $W_{t}=\left(W_{1 t}, \ldots, W_{n t}\right)^{\prime}$ is a $n \times 1$ random vector, and the distribution of the vector $w=\operatorname{vec}\left(W_{1}, \ldots, W_{T}\right)$ conditional on $X$ is either: (i) completely specified (hence, free of nuisance parameters), or (ii) partially specified up to an unknown nuisanceparameter. We call $w$ the vector of normalized disturbances and its distribution the normalized disturbance distribution. When $W_{t}$ has an identity covariance matrix, i.e.

$$
\mathrm{E}\left[W_{t} W_{t}^{\prime}\right]=I_{n}
$$

the matrix $\Sigma=J J^{\prime}$ is the covariance matrix of $V_{t}$, so that $\operatorname{det}(\Sigma) \neq 0$. Note that the assumption (2.10) will not be needed in the sequel. No further regularity conditions are required for most of the statistical procedures proposed below, not even the existence of second moments.

In Beaulieu et al. (2004), we focused on multivariate $t$-distributions and normal mixtures, which we denote $\mathcal{F}_{1}(W)$ and $\mathcal{F}_{2}(W)$ respectively, and define as follows:

$$
W \sim \mathcal{F}_{1}(W ; \kappa) \Leftrightarrow W_{t}=Z_{1 t} /\left(Z_{2 t} / \kappa\right)^{1 / 2},
$$

where $Z_{1 t}$ is multivariate normal $\left(0, I_{n}\right)$ and $Z_{2 t}$ is a $\chi^{2}(\kappa)$ variate independent from $Z_{1 t}$;

$$
W \sim \mathcal{F}_{2}(W ; \pi, \omega) \Leftrightarrow W_{t}=\pi Z_{1 t}+(1-\pi) Z_{3 t},
$$

where $Z_{3 t}$ is multivariate normal $\left(0, \omega I_{n}\right)$ and is independent from $Z_{1 t}$, and $0<\pi<1$.

In the present paper, we extend our empirical investigation to asymmetric stable distributions

$$
W \sim \mathcal{F}_{s}\left(W ; \alpha_{s}, \beta_{s}\right) \Leftrightarrow W_{t i} \stackrel{\text { i.i.d. }}{\sim} S\left(\alpha_{s}, \beta_{s}\right), \quad i=1, \ldots, n,
$$

where $S\left(\alpha_{s}, \beta_{s}\right)$ represents the stable distribution with the tail thickness $\alpha_{s}$, skewness parameter 
$\beta_{s}$, location parameter zero and scale parameter one. In view of the presence of a regression model (2.1) and the $J$ matrix in (2.9), the location and scale parameters of $W_{t}$ can be set to zero and one without loss of generality (and for identification purposes). As it is well known, a simple closedform expression is not available for stable distributions (except in special cases) but there is one for the characteristic function $\phi(t):$ if $S \sim S\left(\alpha_{s}, \beta_{s}\right)$,

$$
\ln \phi(t)=\ln \mathrm{E}[\exp (i t S)]= \begin{cases}-|t|^{\alpha_{s}}\left[1-i \beta_{s} \operatorname{sgn}(t) \tan \left(\pi \alpha_{s} / 2\right)\right], & \text { for } \alpha_{s} \neq 1 \\ -|t|\left[1+i \beta_{s}(2 / \pi) \operatorname{sgn}(t) \ln |t|\right], & \text { for } \alpha_{s}=1\end{cases}
$$

where $0<\alpha_{s} \leq 2$ and $-1 \leq \beta_{s} \leq 1$, and $\operatorname{sgn}(t)$ is the sign function, i.e.

$$
\operatorname{sgn}(t)= \begin{cases}1, & \text { if } t>0 \\ 0, & \text { if } t=0 \\ -1, & \text { if } t<0\end{cases}
$$

see Rachev and Mittnik (2000, Chapter 2) and Samorodnitsky and Taqqu (1994, Chapter 1). Note also that random variables with stable distributions can easily be simulated; see Chambers, Mallows and Stuck (1976) and Weron (1996).

For further reference, we use the following notation:

$$
W \sim \mathcal{F}_{i}(W ; \nu), i=1,2
$$

where $\nu$ is the vector of nuisance parameters in the distribution of $W$, for example

$$
\begin{aligned}
& \nu=\kappa, \quad \text { if } W_{t} \text { satisfies (2.11), } \\
& =(\pi, \omega), \quad \text { if } W_{t} \text { satisfies (2.12), } \\
& =\left(\alpha_{s}, \beta_{s}\right) \text {, if } W_{t} \text { satisfies (2.13). }
\end{aligned}
$$

In the sequel, we shall focus on the third case where $\nu=\left(\alpha_{s}, \beta_{s}\right)$ may be unknown. ${ }^{5}$

\section{Statistical method}

As in Gibbons et al. (1989), the statistic we use to test $H_{C A P M}$ in (2.2) is the Gaussian quasi maximum likelihood (QMLE) based criterion:

$$
L R=T \ln (\Lambda), \quad \Lambda=\left|\hat{\Sigma}_{C A P M}\right| /|\hat{\Sigma}|,
$$

where $\hat{\Sigma}=\hat{U}^{\prime} \hat{U} / T, \hat{U}=Y-X \hat{B}, \hat{B}=\left(X^{\prime} X\right)^{-1} X^{\prime} Y$ and $\hat{\Sigma}_{C A P M}$ is the Gaussian QMLE under $H_{C A P M}$. In Beaulieu et al. (2004), we derive the exact null distribution of the latter statistic under (2.1) and (2.9). This result is reproduced here for convenience.

\footnotetext{
${ }^{5}$ For a theoretical discussion of the CAPM with stable Paretian laws, see Samuelson (1967). For discussions of the class of return distributions compatible with the CAPM, see Ross (1978), Chamberlain (1983), Ingersoll (1987, Chapter 4), Nielsen (1990), Allingham (1991), Berk (1997) and Dachraoui and Dionne (2003).
} 
Theorem 3.1 Distribution OF THE QUASI-LR CAPM TEST STATISTIC. Under (2.1), (2.2) and (2.9), the LR statistic defined by (3.16) is distributed like

$$
T \ln \left(\left|W^{\prime} M W\right| /\left|W^{\prime} M_{0} W\right|\right)
$$

where

$$
\begin{gathered}
M=I-X\left(X^{\prime} X\right)^{-1} X^{\prime}, \\
M_{0}=M+X\left(X^{\prime} X\right)^{-1} H^{\prime}\left[H\left(X^{\prime} X\right)^{-1} H^{\prime}\right]^{-1} H\left(X^{\prime} X\right)^{-1} X^{\prime}, \\
X=\left[\iota_{T}, \tilde{r}_{\mathrm{M}}\right], \quad \tilde{r}_{\mathrm{M}}=\left(\tilde{r}_{1 \mathrm{M}}, \ldots, \tilde{r}_{T \mathrm{M}}\right)^{\prime},
\end{gathered}
$$

$H$ is the row vector $(1,0)$, and $W=\left[W_{1}, \ldots, W_{T}\right]^{\prime}$ is defined by $(2.9)$.

We exploit two results regarding this distribution, the first one being a special case of the latter. First, Theorem 3.1 leads to Gibbons et al. (1989)'s results. Specifically, when errors are Gaussian,

$$
\frac{T-s-n}{n}(\Lambda-1) \sim F(n, T-s-n),
$$

which yields Hotelling's $T^{2}$ test proposed by MacKinlay (1987) and Gibbons et al. (1989). Second, under the general assumption (2.9), the null distribution of (3.16) does not depend on $B$ and $\Sigma$ and may thus easily be simulated if draws from the distribution of $W_{1}, \ldots, W_{T}$ are available. This entails that a Monte Carlo exact test procedure [Dufour (2002)] may be easily applied based on $L R$. The general simulation-based algorithm which allows to obtain a MC size-correct exact $p$-value for all hypotheses conforming with (2.9) and (2.15) is presented in Beaulieu et al. (2004) and may be summarized as follows.

Given $\nu$ in (2.15), generate $N$ i.i.d. draws from the distribution of $W_{1}, \ldots, W_{T}$; on applying (3.17), these yield $N$ simulated values of the test statistic. The exact Monte Carlo $p$-value is then calculated from the rank of the observed $L R$ [denoted by $L R_{0}$ ] relative to the simulated ones:

$$
\hat{p}_{N}\left(L R_{0} \mid \nu\right)=\frac{N \hat{G}_{N}\left(S_{0}\right)+1}{N+1}
$$

where $N \hat{G}_{N}\left(L R_{0}\right)$ is the number of simulated criteria not smaller than $L R_{0}$.

In Beaulieu et al. (2004) we also consider testing $H_{C A P M}$ (2.2) in the context of

$$
r_{i t}=a_{i}+\sum_{j=1}^{s} b_{j i} \tilde{r}_{j t}+u_{i t}, \quad t=1, \ldots, T, i=1, \ldots, n,
$$

where $\tilde{r}_{j t}=\tilde{R}_{j t}-R_{t}^{F}$ and $\tilde{R}_{j t}, j=1, \ldots, s$, are returns on $s$ benchmark portfolios. In this case, the null distribution of the statistic defined by (3.16) obtains as in Theorem 3.1 where

$$
X=\left[\iota_{T}, \tilde{r}_{1}, \ldots, \tilde{r}_{s}\right], \quad \tilde{r}_{j}=\left(\tilde{r}_{1 j}, \ldots, \tilde{r}_{T j}\right)^{\prime}
$$


and $H$ is the $(s+1)$ dimensional row vector $(1,0, \ldots, 0)$.

Let us now extend the above results to the unknown distributional parameter case for the error families of interest, namely (2.15). The $\alpha$-level procedure adopted in Beaulieu et al. (2004) [based on Dufour (1990) and Dufour and Kiviet (1996)] involves two stages: (1) build an exact confidence set [denoted $\mathcal{C}(Y)$ ] for $\nu$, with level $\left(1-\alpha_{1}\right)$; (2) maximize the $p$-value function $\hat{p}_{N}\left(L R_{0} \mid \nu\right)$ in (3.21) over-all values of $\nu$ in the latter confidence set; then compare the latter maximal $p$-value with $\alpha_{2}$ where $\alpha=\alpha_{1}+\alpha_{2}{ }^{6}{ }^{6}$ Formally, the test we denote maximized MC (MMC) test, is significant if

$$
Q_{U}(\nu) \leq \alpha_{2}
$$

where

$$
Q_{U}(\nu)=\sup _{\nu \in \mathcal{C}(Y)} \hat{p}_{N}\left(L R_{0} \mid \nu\right)
$$

To obtain $\mathcal{C}(Y)$, we proceed by "inverting" a goodness-of-fit (GF) test for the null hypothesis (2.15) where $\nu=\nu_{0}$ for known $\nu_{0}$, as proposed in Dufour et al. (2003). The GF test statistic is based on the following excess skewness and kurtosis criteria:

$$
\begin{aligned}
\operatorname{ESK}\left(\nu_{0}\right) & =\left|\mathrm{SK}-\overline{\operatorname{SK}}\left(\nu_{0}\right)\right|, \\
\operatorname{EKU}\left(\nu_{0}\right) & =\left|\operatorname{KU}-\overline{\operatorname{KU}}\left(\nu_{0}\right)\right|,
\end{aligned}
$$

where SK and KU are the well known multivariate measures [see Mardia (1970)]:

$$
\begin{aligned}
\mathrm{SK} & =\frac{1}{T^{2}} \sum_{t=1}^{T} \sum_{i=1}^{T} \hat{d}_{i i}^{3}, \\
\mathrm{KU} & =\frac{1}{T} \sum_{t=1}^{T} \hat{d}_{t t}^{2},
\end{aligned}
$$

$\hat{d}_{i t}$ are the elements of the matrix $\hat{D}=\hat{U}\left(\hat{U}^{\prime} \hat{U}\right)^{-1} \hat{U}^{\prime}$ and $\overline{\mathrm{SK}}\left(\nu_{0}\right)$ and $\overline{\mathrm{KU}}\left(\nu_{0}\right)$ are simulation-based estimates of the expected SK and KU given (2.15). Given $\nu_{0}$, these may be obtained by drawing $N_{0}$ samples of $T$ observations from (2.15), and then computing the corresponding average measures of skewness and kurtosis. ${ }^{7}$ Specifically, we use the combined criterion

$$
\left.\operatorname{CSK}=1-\min \left\{\hat{p}\left(\operatorname{ESK}\left(\nu_{0}\right) \mid \nu_{0}\right), \hat{p}\left(\operatorname{EKU}\left(\nu_{0}\right) \mid \nu_{0}\right)\right)\right\}
$$

where $\hat{p}_{N}\left(\operatorname{ESK}\left(\nu_{0}\right) \mid \nu_{0}\right)$ and $\hat{p}_{N}\left(\operatorname{EKU}\left(\nu_{0}\right) \mid \nu_{0}\right)$ are $\operatorname{MC} p$-values based on $\operatorname{ESK}\left(\nu_{0}\right)$ and $\operatorname{EKU}\left(\nu_{0}\right) .{ }^{8}$ The intuition underlying this combined criterion is to reject the null hypothesis if at

\footnotetext{
${ }^{6}$ In the empirical section, we use $\alpha_{1}=\alpha_{2}=\alpha / 2$.

${ }^{7}$ For the Gaussian case, one may use $\overline{\mathrm{SK}}=0$ and $\overline{\mathrm{KU}}=n(n+2)$; see Mardia (1970).

${ }^{8}$ In Beaulieu et al. (2004), we demonstrate that these criteria are pivotal, i.e. under (2.15), their null distribution does not depend on $B$ and $\Sigma$ and thus may easily be simulated if draws from the distribution of $W_{1}, \ldots, W_{T}$ are available. Hence the MC $p$-values $\hat{p}_{N}\left(\operatorname{ESK}\left(\nu_{0}\right) \mid \nu_{0}\right)$ and $\hat{p}_{N}\left(\operatorname{EKU}\left(\nu_{0}\right) \mid \nu_{0}\right)$ can be obtained following the same simulation technique underlying $\hat{p}_{N}\left(L R_{0} \mid \nu\right)$; see (3.21).
} 
Table 1. Portfolio definitions

\begin{tabular}{ccc}
\hline Portfolio number & Industry Name & Two-digit SIC codes \\
\hline 1 & Petroleum & 13,29 \\
2 & Finance and real estate & $60-69$ \\
3 & Consumer durables & $25,30,36,37,50,55,57$ \\
4 & Basic industries & $10,12,14,24,26,28,33$ \\
5 & Food and tobacco & $1,20,21,54$ \\
6 & Construction & $15-17,32,52$ \\
7 & Capital goods & $34,35,38$ \\
8 & Transportation & $40-42,44,45,47$ \\
9 & Utilities & $46,48,49$ \\
10 & Textile and trade & $22,23,31,51,53,56,59$ \\
11 & Services & $72,73,75,80,82,89$ \\
12 & Leisure & $27,58,70,78,79$ \\
\hline
\end{tabular}

Note - This table presents portfolios according to their number and sector as well as the SIC codes included in each portfolio using the same classification as Breeden et al. (1989).

least one of the individual tests is significant; for convenience, we subtract the minimum $p$-value from one to obtain a right-sided test. The $\mathrm{MC}$ test technique is once again applied to obtain a test based on the combined statistic; details of the algorithm can be found in Dufour et al. (2003) and Beaulieu et al. (2004). For further reference on such combined tests, see Dufour and Khalaf (2002a) and Dufour et al. (2004).

\section{Empirical analysis}

Our empirical analysis focuses on testing (2.2) in the context of (2.1) with different distributional assumptions on stock market returns. We use nominal monthly returns over the period going from January 1926 to December 1995, obtained from the University of Chicago's Center for Research in Security Prices (CRSP). As in Breeden, Gibbons and Litzenberger (1989), our data include 12 portfolios of New York Stock Exchange (NYSE) firms grouped by standard two-digit industrial classification (SIC). Table 1 provides a list of the different sectors used as well as the SIC codes included in the analysis. ${ }^{9}$ For each month the industry portfolios comprise those firms for which the return, price per common share and number of shares outstanding are recorded by CRSP. Furthermore, portfolios are value-weighted in each month. In order to assess the testable implications of the asset pricing models, we proxy the market return with the value-weighted NYSE returns, also available from CRSP. The risk-free rate is proxied by the one-month Treasury Bill rate, also from CRSP.

Our results are summarized in Tables 2 - 4. All MC tests were applied with $N=999$ replications. As usual in this literature, we estimate and test the model over intervals of 5 years. ${ }^{10}$ In

\footnotetext{
${ }^{9}$ As in Breeden et al. (1989), firms with SIC code 39 (Miscellaneous manufacturing industries) are excluded from the dataset for portfolio formation.

${ }^{10}$ Note that we also ran the analysis using ten year subperiods and that our results were not significantly affected.
} 
Table 2. CAPM tests

\begin{tabular}{|c|c|c|c|c|c|c|c|c|c|c|}
\hline \multirow[b]{3}{*}{ Sample } & \multirow[t]{2}{*}{ (1) } & \multirow[t]{2}{*}{ (2) } & \multirow[t]{2}{*}{ (3) } & (4) & (5) & (6) & (7) & (8) & (9) & (10) \\
\hline & & & & \multicolumn{2}{|c|}{ Student $t$} & \multicolumn{2}{|c|}{$\begin{array}{c}\text { Stable symmetric } \\
\beta_{s}=0\end{array}$} & $\begin{array}{r}\mathrm{S} \\
\beta_{s}>0\end{array}$ & $\begin{array}{l}\text { le asym } \\
\beta_{s}<0\end{array}$ & $\beta_{s} \neq 0$ \\
\hline & $Q L R$ & $p_{\infty}$ & $p_{\mathcal{N}}$ & $Q_{U}$ & $C(Y)$ & $Q_{U}$ & $C(Y)$ & $Q_{U}$ & $Q_{U}$ & $C(Y)$ \\
\hline $1927-30$ & 16.10 & .187 & .364 & .357 & $3-12$ & .367 & $1.38-1.96$ & .927 & .941 & $1.44-1.94$ \\
\hline $1931-35$ & 16.26 & .180 & .313 & .322 & $3-8$ & .298 & $1.34-1.92$ & .926 & .925 & $1.42-1.92$ \\
\hline $1936-40$ & 16.02 & .190 & .319 & .333 & $4-26$ & .316 & $1.56-1.98$ & .737 & .764 & $1.56-1.98$ \\
\hline $1941-45$ & 25.87 & .011 & .045 & .049 & $\geq 5$ & .031 & $1.58-1.98$ & .324 & .285 & $1.56-1.98$ \\
\hline $1946-50$ & 37.20 & .000 & .003 & .004 & $4-26$ & .002 & $1.56-1.98$ & .108 & .082 & $1.56-1.98$ \\
\hline $1951-55$ & 36.51 & .000 & .004 & .005 & $5-31$ & .001 & $1.56-1.98$ & .084 & .048 & $1.56-1.98$ \\
\hline $1956-60$ & 43.84 & .000 & .002 & .002 & $\geq 5$ & .001 & $1.56-$ & .032 & .014 & $1.58-1.98$ \\
\hline $1961-65$ & 39.10 & .000 & .002 & .002 & $\geq 7$ & .001 & $1.66-2$ & .044 & .020 & $1.20-1.99$ \\
\hline $1966-70$ & 36.79 & .000 & .003 & .003 & $\geq 5$ & .001 & $1.56-1.98$ & .116 & .044 & $1.58-1.99$ \\
\hline $1971-75$ & 21.09 & .049 & .120 & .129 & $4-24$ & .111 & $1.56-1.98$ & .566 & .596 & $1.56-1.98$ \\
\hline $1976-80$ & 28.37 & .005 & .023 & .026 & $4-17$ & .017 & $1.50-1.98$ & .425 & .329 & $1.50-1.98$ \\
\hline $1981-85$ & 27.19 & .007 & .033 & .035 & $5-34$ & .023 & $1.56-1.98$ & .324 & .309 & $1.56-1.98$ \\
\hline $1986-90$ & 35.75 & .001 & .003 & .005 & $\geq 5$ & .004 & $1.62-2.00$ & .086 & .058 & $1.63-1.99$ \\
\hline 1991-95 & 16.75 & .159 & .299 & .305 & $\geq 15$ & .287 & $1.68-2.00$ & .473 & .477 & $1.70-1.99$ \\
\hline
\end{tabular}

Note - Column (1) presents the quasi-LR statistic defined in (3.16) to test $H_{C A P M}$ [see (2.2)]; columns (2), (3), (4), (6), (8) and (9) are the associated $p$-values using, respectively, the asymptotic $\chi^{2}(n)$ distribution, the pivotal statistics based MC test method imposing multivariate normal regression errors, an MMC confidence set based method imposing, in turn, multivariate $t(\kappa)$ errors, symmetric stable and asymmetric stable errors, which yields the largest MC $p$-value for all nuisance parameters within the specified confidence sets. The latter are reported in columns (5), (7) and (10); for convenience, for the asymmetric stable case, we present the union of the confidence sets for $\alpha_{s}$ given $\beta_{s} \neq 0$. October 1987 and January returns are excluded from the dataset. 
columns (1), (2), (6), (8) and (9) of Table 2, we present the LR and its asymptotic $\chi^{2}(n) p$-value $\left(p_{\infty}\right)$, and stable errors based on maximal MC $p$-values $\left(Q_{U}\right)$. For comparison purposes, we also report [in columns (3) - (4)] the Gaussian based MC $p$-value $p_{\mathcal{N}}$ and the Student- $t$ MMC $p$-value $\left(Q_{U}\right)$ from Beaulieu et al. (2004). The confidence sets $\mathcal{C}(Y)$ for the nuisance parameters appear in columns (5), (7) and (10). To simplify the presentation, the confidence region is summarized as follows: we present the confidence sets for $\alpha_{s}$ given $\beta_{s}=0$, and the union of the confidence sets for $\alpha_{s}$ given $\beta_{s} \neq 0$. These results allow one to compare rejection decisions across different distributional assumptions for the returns of the 12 portfolios.

Our empirical evidence shows the following. In general, asymptotic $p$-values are quite often spuriously significant (e.g. 1941-55). Furthermore, non-Gaussian based maximal $p$-values exceed the Gaussian-based $p$-value. Note however that the results of exact goodness-of-fit tests [available from Dufour et al. (2003)] indicate that normality is definitively rejected except in 1961-65 and 1991-95.

As emphasized in Beaulieu et al. (2004), it is "easier" to reject the testable implications under normality, and any symmetric error considered. Indeed, at the 5\% significance level, we find ten rejections of the null hypothesis for the asymptotic $\chi^{2}(11)$ test, nine for the MC $p$-values under normality, eight under a symmetric stable error distribution, and just two rejections [1956-60, 196165] with left-skewed (negative $\beta_{s}$ ) asymmetric stable errors; no rejections are noted with rightskewed (positive $\beta_{s}$ ) asymmetric stable errors. Note that our MC tests under non-normal errors are joint tests for nuisance parameters consistent with the data and the mean-variance efficiency hypothesis. Since we used $\alpha_{1}=0.025$ for the construction of the confidence set, to establish a fair comparison with the MC $p$-values under the normality assumption or the asymptotic $p$-values, we must refer the $p$-values for the efficiency tests under the Student and the mixtures of normals distributions to $2.5 \% .^{11}$

An important issue here concerns the effect of asymmetries. Consider for instance the subperiods 1941-45, 1976-80 and 1981-85. With Student $t$ errors, the $p$-values for these subperiods are not significant since they exceed $2.5 \%$, yet they remain below $5 \%$. Although we emphasize the importance of accounting for the joint characteristic of our null hypothesis, this result remains empirically notable. The results of the symmetric stable errors are not substantially different from those of the elliptical distributions. This result is interesting since it is often postulated that extreme kurtosis may affect the CAPM test. However, when asymmetries are introduced, the $p$-values are definitively larger and not significant.

The results for the stable distribution differ in one important aspect from the case of elliptical errors. Interestingly, we have observed that the MC $p$-values increase almost monotonically with $\beta_{s}$ and decrease almost monotonically with $\alpha_{s}$ (for $\beta_{s}>0$ and $\alpha_{s}<2$ ); recall that $\beta_{s}=0$ and $\alpha_{s}=2$ lead to the Gaussian distribution. In other words, the MC test is less likely to reject the no-abnormal returns null hypothesis the more pronounced skewness and kurtosis are modelled into the underlying regression errors. Furthermore, quite regularly, throughout our data set, the maximal

\footnotetext{
${ }^{11}$ In this regard, we emphasize that the $2.5 \%$ level allotted to the distributional GF pre-test should not be perceived as an efficiency loss. From an empirical perspective, considering a distribution which is not supported by the data is clearly uninteresting; consequently, disregarding the joint characteristic of the null hypothesis (beside the fact that it is a statistical error) causes flawed and misleading decisions.
} 
Table 3. Supremum $p$-values for various positive skewness measures

\begin{tabular}{c|cccccccc}
\hline$\beta_{s}$ & 0 & .3 & .4 & .5 & .6 & .7 & .9 & .99 \\
\hline $1927-30$ & .367 & .540 & .665 & .777 & .759 & .798 & .888 & .927 \\
$1931-35$ & .298 & .549 & .640 & .744 & .876 & .919 & .907 & .926 \\
$1936-40$ & .316 & .395 & .456 & .521 & .538 & .639 & .688 & .737 \\
$1941-45$ & .031 & .052 & .070 & .096 & .129 & .170 & .276 & .324 \\
$1946-50$ & .002 & .004 & .006 & .010 & .017 & .034 & .080 & .108 \\
$1951-55$ & .001 & .003 & .004 & .007 & .018 & .030 & .058 & .084 \\
$1956-60$ & .001 & .002 & .002 & .002 & .003 & .006 & .020 & .032 \\
$1961-65$ & .002 & .002 & .002 & .002 & .003 & .008 & .017 & .044 \\
$1966-70$ & .001 & .002 & .009 & .010 & .021 & .034 & .080 & .116 \\
$1971-75$ & .011 & .154 & .199 & .246 & .299 & .362 & .490 & .566 \\
$1976-80$ & .017 & .033 & .063 & .106 & .166 & .197 & .418 & .425 \\
$1981-85$ & .023 & .043 & .052 & .079 & .116 & .164 & .277 & .324 \\
$1986-90$ & .004 & .006 & .010 & .013 & .019 & .022 & .063 & .086 \\
$1991-95$ & .287 & .296 & .307 & .324 & .358 & .388 & .443 & .473 \\
\hline
\end{tabular}

Note - Numbers shown are $p$-values associated with our efficiency test using an MMC confidence set based method imposing asymmetric stable errors, which yields, given the specific $\beta_{s}>0$, the largest MC $p$-value for all $\alpha_{s}$ within the specified confidence sets. The latter are reported in Table 2. October 1987 and January returns are excluded from the dataset.

Table 4. Supremum $p$-values for various negative skewness measures

\begin{tabular}{c|ccccccc}
\hline$\beta_{s}$ & 0 & -1 & -.3 & -.5 & -.7 & -.9 & -.99 \\
\hline $1927-30$ & .367 & .363 & .539 & .758 & .830 & .929 & .941 \\
$1931-35$ & .298 & .330 & .517 & .761 & .906 & .918 & .925 \\
$1936-40$ & .316 & .320 & .408 & .563 & .651 & .764 & .740 \\
$1941-45$ & .031 & .340 & .039 & .077 & .152 & .233 & .285 \\
$1946-50$ & .002 & .002 & .002 & .006 & .026 & .050 & .082 \\
$1951-55$ & .001 & .001 & .002 & .009 & .028 & .048 & .038 \\
$1956-60$ & .001 & .002 & .001 & .002 & .002 & .014 & .010 \\
$1961-65$ & .001 & .002 & .002 & .002 & .004 & .012 & .020 \\
$1966-70$ & .001 & .002 & .002 & .008 & .014 & .032 & .044 \\
$1971-75$ & .011 & .110 & .146 & .257 & .382 & .545 & .596 \\
$1976-80$ & .017 & .017 & .024 & .073 & .149 & .281 & .329 \\
$1981-85$ & .023 & .025 & .033 & .079 & .128 & .309 & .285 \\
$1986-90$ & .004 & .004 & .005 & .014 & .020 & .043 & .058 \\
$1991-95$ & .287 & .283 & .297 & .346 & .355 & .405 & .477 \\
\hline
\end{tabular}

Note - Numbers shown are $p$-values associated with our efficiency test using an MMC confidence set based method imposing asymmetric stable errors, which yields, given the specific $\beta_{s}<0$, the largest MC $p$-value for all $\alpha_{s}$ within the specified confidence sets. The latter are reported in Table 2. October 1987 and January returns are excluded from the dataset. 
$p$-value corresponds to the error distribution whose parameters are the smallest $\alpha_{s}$ and the largest $\beta_{s}$ not rejected by our GF test. This monotonicity with respect to nuisance parameters (which we did not observe under elliptical errors) is notable. Of course, it also emphasizes the importance of our two-step test procedures which allows to rule-out the values of $\alpha_{s}$ and $\beta_{s}$ not supported by the data.

A simulation study conducted on the power of these GF tests (not reported here, but available from the authors upon request) reveals that while $\alpha_{s}$ is well estimated, the precision of the estimation of $\beta_{s}$ raises further challenges. To the best of our knowledge however, the inference procedures we apply in this paper are the only exact ones available to date. Here we show that the difficulty in estimating the skewness parameter has crucial implications for asset pricing tests. This result provides motivation to pursue research on exact approaches to the estimation of stable laws.

\section{Conclusion}

In this paper, we have proposed likelihood based exact asset-pricing tests allowing for highdimensional non-Gaussian and non-regular distributional frameworks. We specifically illustrate how to deal in finite samples with elliptical and stable errors with possibly unknown parameters. The tests suggested were applied to an efficiency problem in a standard asset pricing model framework with CRSP data.

Our empirical analysis reveals that abnormal returns are less prevalent when skewness is empirically allowed for; in addition, the effects of extreme kurtosis in the errors on test $p$-values are less marked than the effects of skewness. We view these results as a motivation for assessing the skewness corrected versions of the CAPM [introduced by Kraus and Litzenberger (1976) among others]. The regression model with stable errors provides an initial framework to assess asset pricing anomalies by modelling skewness via unobservables. Other skewness-justified approaches include: (i) extra pricing factors [see Fama and French (1993), Fama and French (1995), Harvey and Siddique (2000)] added to the regression, or (ii) the two-factor regression model of Barone-Adesi (1985) and Barone-Adesi, Gagliardini and Urga $(2004 a, 2004 b)$. To the best of our knowledge, the threemoments CAPM has been tested with procedures which are only asymptotically valid, even under normality. Our framework easily allows one to deal with multi-factor models; however, BaroneAdesi (1985)'s model and its recent modification analyzed by Barone-Adesi, Gagliardini and Urga (2004a, 2004b) impose non-linear constraints. The latter empirical tests have not been reconsidered to date with reliable finite sample techniques. The development of exact versions of these tests and of alternative versions which correct for skewness is an appealing idea for future research. 


\section{References}

Adler, R., Feldman, R. and Taqqu, M. S., eds (2000), A Practical Guide to Heavy Tails: Statistical Techniques for Analyzing Heavy Tailed Distributions, Birkaüser, Boston, New Jersey.

Allingham, M. (1991), 'Existence theorems in the capital asset pricing model', Econometrica 59, 1169-1174.

Anderson, T. W. (1984), An Introduction to Multivariate Statistical Analysis, second edn, John Wiley \& Sons, New York.

Baillie, R. and Bollerslev, T. (1989), 'The message in daily exchange rates: A conditional variance tale', Journal of Business and Economic Statistics 7, 297-305.

Barnard, G. A. (1963), 'Comment on 'The spectral analysis of point processes' by M. S. Bartlett', Journal of the Royal Statistical Society, Series B 25, 294.

Barone-Adesi, G. (1985), 'Arbitrage equilibrium with skewed asset returns', Journal of Financial and Quantitative Analysis 20(3), 299-313.

Barone-Adesi, G., Gagliardini, P. and Urga, G. (2004a), A test of the homogeneity hypothesis on asset pricing models, in E. Jurczenko and B. Maillett, eds, 'Multi-Moment CAPM and Related Topics', Springer-Verlag, Berlin.

Barone-Adesi, G., Gagliardini, P. and Urga, G. (2004b), 'Testing asset pricing models with coskewness', Journal of Business and Economic Statistics forthcoming.

Beaulieu, M.-C. (1998), 'Time to maturity in the basis of stock market indices: Evidence from the S\&P 500 and the MMI', Journal of Empirical Finance 5, 177-195.

Beaulieu, M.-C., Dufour, J.-M. and Khalaf, L. (2004), Multivariate tests of mean-variance efficiency with possibly non-Gaussian errors: An exact simulation-based approach, Technical report, Département d'économique, Université Laval, and CIREQ, Université de Montréal.

Berk, J. B. (1997), 'Necessary conditions for the CAPM', Journal of Economic Theory 73, 245-257.

Breeden, D. T., Gibbons, M. and Litzenberger, R. H. (1989), 'Empirical tests of the consumption based CAPM', Journal of Finance 44, 231-262.

Cambanis, S., Samorodnitsky, G. and Taqqu, M. S., eds (1991), Stable Processes and Related Topics: A Selection of Papers from MSI Workshop, Birkhaüser, Boston, Massachusetts.

Campbell, J. Y., Lo, A. W. and MacKinlay, A. C. (1997), The Econometrics of Financial Markets, Princeton University Press, New Jersey.

Chamberlain, G. (1983), 'A characterization of the distributions that imply mean-variance utility functions', Journal of Economic Theory 29, 185-201. 
Chambers, J. M., Mallows, C. L. and Stuck, B. W. (1976), 'A method for simulating stable random variables', Journal of the American Statistical Association 71, 340-344. Correction, 82, 704, 83,581 .

Dachraoui, K. and Dionne, G. (2003), Conditions ensuring the separability of asset demand by all risk averse investors, Technical report, Risk Management Chair, HEC Montréal, Canada.

Dufour, J.-M. (1990), 'Exact tests and confidence sets in linear regressions with autocorrelated errors', Econometrica 58, 475-494.

Dufour, J.-M. (1997), 'Some impossibility theorems in econometrics, with applications to structural and dynamic models', Econometrica 65, 1365-1389.

Dufour, J.-M. (2002), 'Monte Carlo tests with nuisance parameters: A general approach to finitesample inference and nonstandard asymptotics in econometrics', Journal of Econometrics forthcoming.

Dufour, J.-M. (2003), 'Identification, weak instruments and statistical inference in econometrics', Canadian Journal of Economics 36(4), 767-808.

Dufour, J.-M., Farhat, A., Gardiol, L. and Khalaf, L. (1998), 'Simulation-based finite sample normality tests in linear regressions', The Econometrics Journal 1, 154-173.

Dufour, J.-M., Hallin, M. and Mizera, I. (1998), 'Generalized runs tests for heteroskedastic time series', Journal of Nonparametric Statistics 9, 39-86.

Dufour, J.-M. and Khalaf, L. (2001), Monte Carlo test methods in econometrics, in B. Baltagi, ed., 'Companion to Theoretical Econometrics', Blackwell Companions to Contemporary Economics, Basil Blackwell, Oxford, U.K., chapter 23, pp. 494-519.

Dufour, J.-M. and Khalaf, L. (2002a), 'Exact tests for contemporaneous correlation of disturbances in seemingly unrelated regressions', Journal of Econometrics 106(1), 143-170.

Dufour, J.-M. and Khalaf, L. (2002b), 'Simulation based finite and large sample tests in multivariate regressions', Journal of Econometrics 111(2), 303-322.

Dufour, J.-M. and Khalaf, L. (2003), Finite sample tests in seemingly unrelated regressions, in D. E. A. Giles, ed., 'Computer-Aided Econometrics', Marcel Dekker, New York, chapter 2, pp. 11-35.

Dufour, J.-M., Khalaf, L. and Beaulieu, M.-C. (2003), 'Exact skewness-kurtosis tests for multivariate normality and goodness-of-fit in multivariate regressions with application to asset pricing models', Oxford Bulletin of Economics and Statistics 65, 891-906.

Dufour, J.-M., Khalaf, L., Bernard, J.-T. and Genest, I. (2004), 'Simulation-based finite-sample tests for heteroskedasticity and ARCH effects', Journal of Econometrics 122(2), 317-347. 
Dufour, J.-M. and Kiviet, J. F. (1996), 'Exact tests for structural change in first-order dynamic models', Journal of Econometrics 70, 39-68.

Dufour, J.-M. and Kiviet, J. F. (1998), 'Exact inference methods for first-order autoregressive distributed lag models', Econometrica 66, 79-104.

Dwass, M. (1957), 'Modified randomization tests for nonparametric hypotheses', Annals of Mathematical Statistics 28, 181-187.

Embrechts, P., Klüppelberg, C. and Mikosch, T. (1997), Modelling Extremal Events for Insurance and Finance, Springer-Verlag, Berlin.

Fama, E. F. (1965), 'The behaviour of stock prices', Journal of Business 60, 401-424.

Fama, E. F. and French, K. R. (1993), 'Common risk factors in the returns on stocks and bonds', Journal of Financial Economics 33, 3-56.

Fama, E. F. and French, K. R. (1995), 'Size and book-to-market factors in earnings and returns', The Journal of Finance 50, 131-155.

Fama, E. F. and French, K. R. (2003), The CAPM: Theory and evidence, Working paper, Center for Research in Security Prices, The University of Chicago, Chicago, Illinois, and Amos Tuck School of Business, Dartmouth College, Hanover, New Hampshire.

Gibbons, M. R., Ross, S. A. and Shanken, J. (1989), 'A test of the efficiency of a given portfolio', Econometrica 57, 1121-1152.

Harvey, C. R. and Siddique, A. (2000), 'Conditional skewness in asset pricing tests', The Journal of Finance 55, 1263-1295.

Hodgson, D. J., Linton, O. and Vorkink, K. (2002), 'Testing the capital asset pricing model efficiently under elliptical symmetry: A semiparametric approach', Journal of Applied Econometrics 17, 617-639.

Hodgson, D. J. and Vorkink, K. (2003), 'Efficient estimation of conditional asset pricing models', Journal of Business and Economic Statistics 21, 269-283.

Ibragimov, I. A. and Linnik, Y. V. (1975), Independent and Stationary Sequences of Random Variables, Wolters-Nordhoff, Groningen, The Netherlands.

Ingersoll, J. (1987), Theory of Financial Decision Making, Rowman \& Littlefield, NJ.

Jobson, J. D. and Korkie, B. (1989), 'A performance interpretation of multivariate tests of asset set intersection, spanning, and mean-variance efficiency', Journal of Financial and Quantitative Analysis 24, 185-204.

Kiviet, J. F. and Dufour, J.-M. (1997), 'Exact tests in single equation autoregressive distributed lag models', Journal of Econometrics 80, 325-353. 
Kraus, A. and Litzenberger, R. (1976), 'Skewness preference and the valuation of risk assets', Journal of Finance 31, 1085-1100.

Lehmann, E. L. (1986), Testing Statistical Hypotheses, 2nd edition, John Wiley \& Sons, New York.

Li, H. and Maddala, G. S. (1996), 'Bootstrapping time series models', Econometric Reviews 15, 115-158.

MacKinlay, A. C. (1987), 'On multivariate tests of the Capital Asset Pricing Model', Journal of Financial Economics 18, 341-372.

Mandelbrot, B. (1963), 'The variation of certain speculative prices', Journal of Business 36, 394419.

Mardia, K. V. (1970), 'Measures of multivariate skewness and kurtosis with applications', Biometrika 57, 519-530.

Meerschaert, M. M. and Scheffler, H.-P. (2001), Limit Distributions for Sums of Independent Random Vectors: Heavy Tails in Theory and Practice, John Wiley \& Sons, New York.

Mittnik, S., Paolella, M. and Rachev, S. (2000), Stable paretian modeling in finance: Some empirical and theoretical aspects, in (Adler et al. 2000).

Nielsen, L. T. (1990), 'Existence of equilibrium in CAPM', Journal of Economic Theory 52, 223231.

Rachev, S., Kim, J.-R. and Mittnik, S. (1999a), 'Stable paretian econometrics, part I', The Mathematical Scientist 24, 24-55.

Rachev, S., Kim, J.-R. and Mittnik, S. (1999b), 'Stable paretian econometrics, part II', The Mathematical Scientist 24, 113-127.

Rachev, S. and Mittnik, S. (2000), Stable Paretian Models in Finance, John Wiley \& Sons, New York.

Rao, C. R. (1973), Linear Statistical Inference and its Applications, second edn, John Wiley \& Sons, New York.

Ross, S. A. (1978), 'Mutual fund separation in financial theory - The separating distributions', Journal of Economic Theory 17, 254-286.

Samorodnitsky, G. and Taqqu, M. S. (1994), Stable Non-Gaussian Random Processes: Stochastic Models with Infinite Variance, Chapman \& Hall, New York.

Samuelson, P. (1967), 'On multivariate tests of the Capital Asset Pricing Model', Journal of Financial and Quantitative Analysis 2, 107-122. 
Shanken, J. (1996), Statistical methods in tests of portfolio efficiency: A synthesis, in G. S. Maddala and C. R. Rao, eds, 'Handbook of Statistics 14: Statistical Methods in Finance', NorthHolland, Amsterdam, pp. 693-711.

Stewart, K. G. (1997), 'Exact testing in multivariate regression', Econometric Reviews 16, 321-352.

Uchaikin, V. V. and Zolotarev, V. M. (1999), Chance and Stability. Stable Distributions and Their Applications, VSP, Zeist, The Netherlands.

Vorkink, K. (2003), 'Return distributions and improved tests of asset pricing models', The Review of Financial Studies 16(3), 845-874.

Weron, R. (1996), 'On the Chambers-Mallows-Stuck method for simulating skewed stable random variables', Statistics and Probability Letters 28, 165-171.

Zolotarev, V. M. (1986), One-Dimensional Stable Distributions, Vol. 65 of Translations of Mathematical Monographs, American Mathematical Society, Providence, Rhose Island. 